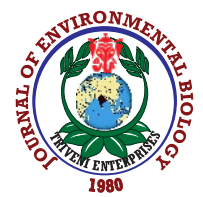

\title{
Effects of oral-dosing of an antiparasitic drug emamectin benzoate on the growth and serum biomarkers of Oreochromis niloticus (L.) juveniles
}

\author{
R.B. Julinta', T.J. Abraham ${ }^{1},{ }^{*}$, A. Roy', J. Singha', G. Dash', T.K. Sar ${ }^{2}$ and P.K. Patil ${ }^{3}$ \\ 'Department of Aquatic Animal Health, Faculty of Fishery Sciences, West Bengal University of Animal and Fishery Sciences, Kolkata-700 094, India \\ ${ }^{2}$ Department of Veterinary Pharmacology, Faculty of Veterinary and Animal Sciences, West Bengal University of Animal and Fishery Sciences, \\ Kolkata-700 037, India \\ ${ }^{3}$ Aquatic Animal Health and Environment Division, ICAR-Central Institute of Brackishwater Aquaculture, Chennai-600 028, India \\ *Corresponding Author Email : abrahamtj1@gmail.com
}

\section{Abstract}

Aim: To assess the effects of an antiparasitic aquadrug emamectin benzoate (EB) on the serum biomarkers of Nile tilapia, Oreochromis niloticus when fed at the recommended dietary dose regimen of $50 \mathrm{~g} \mathrm{~kg} \mathrm{biomass}^{-1}$ day $^{-1}$ for 7 consecutive days (1X) and compare with the control and 10 times the recommended dose (10X).

Methodology: Nile tilapia were divided into three groups of thirty fish each. The fish of Group 1 were fed with control feed. Group 2 and 3 were fed with 50 $\mu \mathrm{g}$ and $500 \mu \mathrm{g} \mathrm{EB} \mathrm{kg} \mathrm{biomass}{ }^{-1}$ day $^{-1}$, respectively, for 7 days followed by 45 days of post-dosing observations. Serum samples from different EB-dosed Nile tilapia were collected at scheduled interludes to analyse the serum biomarkers, viz., glucose, aspartate aminotransferase (AST), alanine aminotransferase (ALT), creatinine and C-reactive protein (CRP) by standard kits.

Results: Seven days of EB-dosing reduced the biomass by $6.91 \%$. The levels of fish serum biomarkers increased significantly on day 7 EB-dosing. Their levels consequently reduced, but did not reach normalcy, except ALT, AST and CRP, on day 45 post-EB-dosing at the recommended dose. The results demonstrated that the physiological state of apparently healthy Nile tilapia was persuaded by oral EB-dosing.

Interpretation: The effects of EB-dosing on serum biomarkers of Nile tilapia are revocable. Nevertheless, the observed results on the biomass reduction and elevated levels of serum biomarkers, raises concern on the effectiveness of oral EB-dosing in Indian condition.

Key words: Anti-parasitic drug, Emamectin benzoate, Oral-dosing, Oreochromis niloticus, Serum biomarkers

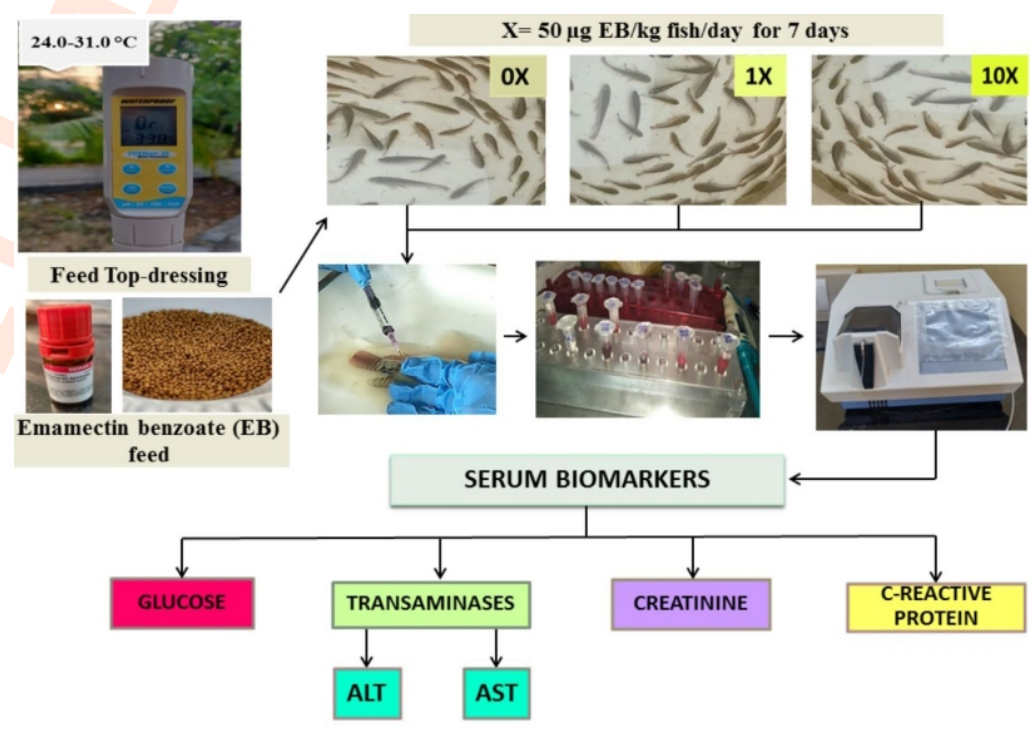

How to cite : Julinta, R.B., T.J. Abraham, A. Roy, J. Singha, G. Dash, T.K. Sar and P.K. Patil: Effects of oral-dosing of an antiparasitic drug emamectin benzoate on the growth and serum biomarkers of Oreochromis niloticus (L.) juveniles. J. Environ. Biol., 41, 973-979 (2020). 


\section{Introduction}

Tilapia is pondered as one of the most widely-farmed and cultured fish globally, owing to its rapid growth rate, acceptance of different dietary protein sources and tolerance to the awful environment (Ng and Romano, 2013). Anti-parasitic drugs are the most widely used tool for managing parasite infections in cultured aquatic species. Although there has been substantial investment into the expansion of novel anti-parasitic drugs, the range of effectual treatments presently existing for use worldwide is extremely limited (Athanassopoulou et al., 2009; Sanders and Swan, 2014). Emamectin benzoate (EB) is formulated and marketed under the trade name SLICE ${ }^{\circledR}$ by Schering-Plough Animal Health (SPAH) presently Merck Animal Health (Sanders and Swan, 2014). It is a member of avermectin family of compounds - a close relative of ivermectin, that is produced by fermentation of soil microorganism Streptomyces avermitilis (Burg and Stapley, 1990). Ivermectin was developed as an antiparasitic agent for livestock, which possessed both contact and systemic activity against immature and adult ectoparasites (Campbell, 1990). The general mode of action of the avermectins is to interrupt the transmission of signals in the nervous system. Avermectins link with many ligand-gated chloride channels, which increase the permeability of cell membrane resulting in dysfunction of nervous system (McKellar and Banchaoui, 1996). Emamectin benzoate is an in-feed treatment that was initially developed to control infestations of sea lice (e.g., Lepeophtheirus salmonis, Caligus elongatus and Caligus rogercresseyi) in seawater-reared salmon and trout (MSD Animal Health, 2012). Contemporary practices of collective in-feed therapy are based on the assumption that medicated feed is equally distributed and consumed within a group of fish and uniformly distributed throughout the therapeutic period, to ensure that each fish receives appropriate dose. Alike sea lice infestation, the freshwater fish are also infested with fish lice Argulus spp., which reportedly cause severe economic losses in carp aquaculture (Sahoo et al., 2013). Addition of SLICE® for controlling external parasites in freshwater fish to aquaculture's approved medicine chest would be a value-added tool to help optimize overall fish health and population fitness. Emamectin benzoate can be an alternative drug if adequate research is undertaken to assess its toxicity in a tropical fish, dose ranges and tissue residue levels. SLICE $®$ has been extensively tested in trials to evaluate environmental safety, efficacy and tolerance in Atlantic salmon Salmo salar, rainbow trout Oncorhynchus mykiss and brown trout Salmo trutta (Stone et al., 1999; Roy et al., 2000; Armstrong et al., 2000) and in goldfish Carassius auratus, koi carp, Cyprinus carpio (Hanson et al., 2011). Nevertheless, additional data are needed to demonstrate the safety of EB for use with tropical freshwater reared fish and to establish an associated margin of biosafety. The present study was, therefore, undertaken to assess the dietary influences of EB on the growth and serum biochemistry of Nile tilapia, Oreochromis niloticus at the recommended dose regimen in a tropical climate.

\section{Materials and Methods}

Test fish: Farm-grown apparently healthy juvenile Nile tilapia, Oreochromis niloticus irrespective of gender were procured from Sonarpur, South 24 Parganas district, West Bengal, India and brought to the laboratory in oxygen-filled polythene bags. The fish, 100 each, were transferred into five circular fiberglass reinforced plastic tanks (FRP) holding 300 I of bore-well water. The fish were acclimatized for three weeks with continuous aeration and fed with pellet diet (CP Private Limited, India) to satiety twice daily. About $50 \%$ of water in the system was replaced every 3 days to avoid accretion of excretory products.

Emamectin benzoate feeds preparation: The recommended dietary dose regimen of EB, administered as Slice $®$, is $50 \mu \mathrm{g} \mathrm{kg}$ biomass $^{-1}$ day $^{-1}$ for 7 consecutive days (MSD Animal Health, 2012). The medicated feeds for feeding the experimental fish at $2 \%$ of body weight were prepared. Emamectin benzoate (SigmaAldrich, India) stock solution was prepared by adding $50 \mathrm{mg}$ EB powder in $5 \mathrm{ml}$ ethyl acetate and $50 \mu \mathrm{l}$ tween 80 , and vortexed for 5 min (Feng et al., 2016). The top dressed EB feeds at a dose of

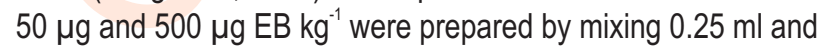
$2.50 \mathrm{ml}$ of EB suspension $\mathrm{kg}^{-1}$ feed, respectively, with $5.0 \mathrm{ml}$ vegetable oil as a binder and then admixing with $1 \mathrm{~kg}$ dry basal feed in order of increasing EB concentration. The contents were thoroughly mixed, spread separately, air-dried at room temperature for $24 \mathrm{hr}$, and stored separately in airtight plastic containers. The control feed without EB was prepared with vegetable oil as a binder at $5 \mathrm{ml} \mathrm{kg}^{-1}$ feed following the above procedure. All feeds were prepared freshly and used instantaneously.

Experimental design and dose administration: Twelve rectangular study tanks $(\mathrm{L} 58 \times \mathrm{H} 45 \times \mathrm{W} 45 \mathrm{~cm})$ with 30 fish $(11.80 \pm 1.55 \mathrm{~cm}$ and $14.40 \pm 1.50 \mathrm{~g})$ each were sequentially numbered and assigned into 3 groups: Group 1: 0X control feed: Group 2: 1X EB-feed (50 $\mu \mathrm{g}$ EB kg fish ${ }^{-1}$ day $^{-1}$ ) and Group 3: 10X EB-feed (500 $\mu \mathrm{g}$ EB kg fish ${ }^{-1}$ day $\left.^{-1}\right)$ in quadruplicate. Prior to transfer, a group of 10 fish from each group were indiscriminately netted and then individually weighed. The EB-medicated feeds were offered as sole ration for 7 consecutive days during the dosing period as per the recommended dosing regimen (Whyte et al., 2011; MSD Animal Health, 2012). One each of the test tank from the respective group was designated as "growth" tank. The fish of such "growth" tanks were fed with the respective feeds during the dosing period as sole diet. The fish in the "growth" tanks were only used to determine growth during the study period so that the quantity of feed offered to experimental fish could be adjusted to accommodate fish growth.

The fish of Group 1 were fed with control feed throughout the experimental period. During pre-dosing period (day 1-7), the fish of Group 2 and 3 were fed with control feed. From day 8-14, the Group 2 and 3 were fed with EB-feeds at $2 \%$ b.wt. thrice daily 
to achieve a concentration of $50 \mu \mathrm{g} \mathrm{EB} \mathrm{kg} \mathrm{fish}{ }^{-1}$ day $^{-1}$ and $500 \mu \mathrm{g}$ EB kg fish ${ }^{-1}$ day $^{-1}$, respectively, for 7 consecutive days. During post-dosing period of 45 days from day 15 to 59 , the fish of all groups were fed with control feed. The amount of feed offered was calculated individually for each tank based on the assessed biomass in that tank. Feed remaining in the tank $\sim 1$ hour after feeding was siphoned from the tank into a pre-weighed container. The biomass of tilapia from each group was determined periodically and the difference in the weight gain for each group was calculated. The survival of experimental fish was also recorded during the experimental period.

Collection of serum and biomarker analyses: The blood samples were collected from three randomly chosen fish on day 0 (pre-dosing), day 1 and day 7 EB-dosing, day 28 and day 45 post$\mathrm{EB}$ dosing from each group during trial period. The fish were anaesthetized with clove oil $\left(20 \mathrm{\mu l} \mathrm{I}^{-1}\right)$ prior to blood collection by caudal vein puncture using $2 \mathrm{ml}$ sterile plastic syringe (Roberts, 2012). The serum was separated by centrifugation (2500 rpm, 15 $\mathrm{min}$ ) and stored at $-20^{\circ} \mathrm{C}$ for further analysis. Serum glucose was measured by glucose oxidase and peroxidase (GOD-POD) method (Trinder, 1969). The serum aspartate aminotransferase (AST) and alanine aminotransferase (ALT) activities were estimated by modified UV (IFCC), kinetic assay method described by Feri et al. (1995). Serum creatinine was determined by modified Jaffe's reaction and C-reactive protein by immunoturbidimetric test following the methods of Junge et al. (2004) and Bakker and Mucke (2007), respectively. All these parameters were determined by standard kits of DiaSys Diagnostic Systems, Germany and Span Diagnostics Limited, India and a photometer (Model: 5010 v5+, Robert Riele KG, Berlin) as per manufacturer's instructions.

Statistical analyses: The experimental design was completely randomized. The results were presented as mean $\pm S D$. The biomass and biochemical data were analysed by ANOVA and Tukey HSD post-hoc for the comparison of means. All these statistical analyses were performed using Statistical Package for Social Sciences (IBM-SPSS) Version: 22.0. A probability level of $\mathrm{P}<0.05$ was considered significant for the experimental data.

\section{Results and Discussion}

Throughout the experimentation, the water quality parameters were maintained ideally within the appropriate ranges required for normal fish growth including tilapia (Boyd, 1979). As shown in Fig. 1, from $1^{\text {st }}$ day of EB-dosing to the end of the experiment (i.e., 8-59 days), the differences in the biomass of 0 . niloticus recorded in control, $1 \mathrm{X}$ EB-feed and 10X EB-feed groups were $90.55 \mathrm{~g}, 84.29 \mathrm{~g}$ and $79.52 \mathrm{~g}$, respectively, which differed significantly $(P<0.05)$. These results indicated a reduced growth of $6.91 \%$ and $12.18 \%$ in the $1 \mathrm{X}$ and $10 \mathrm{X}$ EB-groups from beginning of EB-dosing to the end of the experiment as compared to the control. In contrast, the growth reduction was minimal

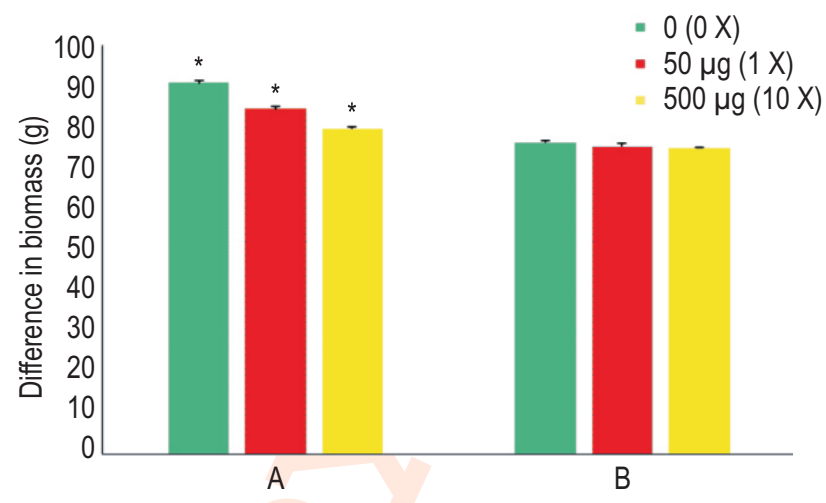

Fig. 1 : Differences in the biomass of emamectin benzoate $(E B)$ fed Oreochromis niloticus at the recommended dose $\left(50 \mu \mathrm{g} \mathrm{kg} \mathrm{fish}^{-1} \mathrm{day}^{-1}\right)$ and ten times the recommended dose $\left(500 \mu \mathrm{g} \mathrm{kg} \mathrm{fish}{ }^{-1}\right.$ day $\left.^{-1}\right)$ for 7 consecutive days. A: Start of EB-dosing to the end of experiment (8-59 days), B: Post-EB dosing period (15-59 days). *: Bars sharing asterisks $\left(^{*}\right)$ among the treatment groups for a particular period of time (A and B) differed significantly $(P>0.05)$

during the post-EB dosing regimen, as an improved feed intake was observed. The biomass differences $(76.14 \mathrm{~g}, 75.23 \mathrm{~g}$ and $74.84 \mathrm{~g}$ ) observed during the post-EB dosing period (i.e., 15-59 days) were, however, insignificant $(P>0.05)$. The growth reduction observed in $1 \mathrm{X}$ and $10 \mathrm{X}$ EB-groups during post- EBdosing period was $1.19 \%$ and $1.70 \%$, respectively, which indicated retrieval of fish growth. The 1X EB-feed and 10X EBfeed groups recorded $98.0 \%$ and $95.5 \%$ survival during dosing period. These results suggested that oral EB-dosing at the recommended dose regimen may result in mortalities $(2 \%)$ and significant decrease in growth in apparently healthy Nile tilapia.

Glucose is the energy source required for vital actions and its level in serum is regulated by the endocrine system (Dange, 1986). The blood glucose level in fish is an imperative criterion for diagnosing of the function of liver and muscle tissues (Chen et al., 2004). The recorded serum glucose levels in control Nile tilapia (59.75-67.00 $\left.\mathrm{mg} \mathrm{dl}^{-1}\right)$ were similar to those observed in different species of tilapia, including 0 . niloticus cultured under different conditions (Hrubec et al., 2000; Mauel et al., 2007; Zaki et al., 2008). The $1 \mathrm{X}$ EB-feed fed group showed a significant increase in glucose level to $91.84 \mathrm{mg} \mathrm{dl}^{-1}$ on day 7 EB-dosing, which then significantly reduced to 85.83 and $70.05 \mathrm{mg} \mathrm{dl}^{-1}$ on day 28 and day 45 post-EB dosing, respectively $(P<0.05)$. The $10 \mathrm{X}$ EB-feed fed fish also followed a similar trend, with the highest glucose level (98.55 $\mathrm{mg} \mathrm{dl}^{-1}$ ) on day 7 EB-dosing, which then reduced significantly to $87.15 \mathrm{mg} \mathrm{dl}^{-1}$ on day 45 post-EB dosing $(P<0.05)$. The increase in serum glucose level was almost 1.85 folds in $1 \mathrm{X}$ EB-feed fed fish (91.84 $\left.\mathrm{mg} \mathrm{dl}^{-1}\right)$ and 1.98 folds in 10X EB feed fed fish ( $98.55 \mathrm{mg} \mathrm{dl}^{-1}$ ) on $7^{\text {th }}$ day of EB-dosing (Fig. 2a). A significant difference was noted in the glucose levels of control and 10X EB-fed groups $(P<0.05)$ on day 1 EB-dosing, possibly due to mobilization of glycogen to meet the extra energy demand 
in the metabolism (Canli, 1996). The impact of EB on this secondary phase stress response was more in 10X initially compared to $1 \mathrm{X}$. This indicated that EB can act as a potential chemical stressor to cultured fish during therapy. MartínezPorchas et al. (2009) stated that the stress conditions appear in fish within minutes or hours after acute stress, and the results of the present study authenticated their explanation as negative effect was felt even on day $1 \mathrm{~EB}$-dosing. The $1 \mathrm{X}$ and $10 \mathrm{X}$ EB-fed groups recorded significantly higher glucose levels on day 45 post-EB dosing compared to day $0(P<0.05)$. Also, the serum glucose levels of $1 \mathrm{X}$ and $10 \mathrm{X}$ EB-dosing groups were significantly different on day 28 and day 45 post-EB dosing, possibly due to the elevated EB-induced stress at highest dose. Though its level reduced significantly on day 28 and day 45 post -EB dosing, the levels were still significantly higher than the initial levels recorded on day 0 . These fallouts projected that EB-induced stress and the physiological responses persisted and fish could not recover fully even after 45 days of cessation of EB-dosing.

If any damage occurs to the tissues, the enzymes ALT and AST are leaked out of the cell in order to neutralize the toxic substances (Barraza et al., 1991). Chen et al. (2004) related the increased levels of these two enzymes in tilapia with hepatic injury. The present study documented serum ALT levels in the range of 23.50-33.50 $\mathrm{IUI}^{-1}$ in the control group, which were higher than those of the earlier studies, possibly due to varied genetic stocks used in different geographical locations. For instance, the normal ALT values ranged between 5 and $21 \mathrm{IUI}^{-1}$ in healthy tilapia raised in different production systems (Hrubec et al., 2000; Chen et al., 2003). There was a significant increase in the ALT level $\left(48.50 \mathrm{IU}^{-1}\right)$ of $1 \mathrm{X}$ EB-feed fed fish on day $7 \mathrm{~EB}$-dosing $(\mathrm{P}<0.05)$, which reduced significantly to $39.40 \mathrm{IUI}^{-1}$ and $25.00 \mathrm{UI} \mathrm{I}^{-1}$ on day 28 and day 45 post-EB dosing, respectively $(P<0.05)$. An equal trend was noted in the ALT levels of 10X EB-fed fish with a significant rise to $64.50 \mathrm{IUl}^{-1}$ on day $7 \mathrm{~EB}$-dosing $(\mathrm{P}<0.05)$, which on day 28 and day 45 post-EB dosing reduced significantly to 41.00 and $33.50 \mathrm{IUI}^{-1}$, respectively $(\mathrm{P}<0.05)$. The increase in the ALT levels was almost 2.06 folds in the $1 \mathrm{X}$ group and by 2.74 folds in the $10 \mathrm{X}$ group in 7 days of EB-dosing (Fig. 2b). These results demonstrated that EB can impede the protein and amino acid metabolism in the liver. The impact of EB-dosing was spotted even on day 1 as the difference in the serum ALT level was significant compared to day 0 in a dose-dependent manner. The effect of EB on this biomarker of liver function was more distinct in the 10X group. The difference in the serum ALT levels of $1 \mathrm{X}$ and 10X EB-groups on day 45 post-EB dosing was significant $(P<0.05)$, possibly due to the EB-induced stress at the highest dose. The ALT levels of the 10X group were, however, significantly higher than the initial levels recorded on day 0 .

The serum AST levels (22.50-32.65 IU I') recorded in control group was within the minimum levels $\left(9-40 \mathrm{IU} \mathrm{I}^{-1}\right)$ noted in hybrid tilapia raised in high-density production systems (Hrubec et al., 2000) and recirculating system (Mauel et al., 2007). The $1 X$
EB-feed fed group exhibited a significant upsurge in the AST level to $48.50 \mathrm{IU} \mathrm{I}^{-1}$ on day $7 \mathrm{~EB}$-dosing, which then significantly declined to 38.00 and $25.00 \mathrm{IU} \mathrm{I}^{-1}$ on day 28 and day 45 post-EB dosing, respectively $(P<0.05)$. The $10 X$ EB-feed fed group also had an analogous trend where a significant rise of $55.50 \mathrm{U} \mathrm{I}^{-1}$ and $59.00 \mathrm{IU} \mathrm{I}^{-1}$ were observed on the day 1 and 7 EB-dosing, respectively $(P<0.05)$, which then significantly reduced to 47.65 and $30.50 \mathrm{IU} \mathrm{I}^{-1}$ on day 28 and day 45 post-EB dosing $(\mathrm{P}<0.05)$. The effect of EB was evident on day $1 \mathrm{~EB}$-dosing and the increase was found to be dose-dependent (Fig. 2c). An increased AST level by 2.06 folds in $1 \mathrm{X}$ group and by 2.51 folds in $10 \mathrm{X}$ group in 7 days of EB-dosing obviously projected EB as an inducer of hepatic dysfunction in Nile tilapia, possibly due to disturbance of nitrogen metabolism, damage of hepatic cells, disrupted Kreb's cycle and other hepato-cellular damage (Chen et al., 2004; Manjunatha et al., 2015). The AST levels of control and $1 \mathrm{X}$ groups were significantly different on day 1 and day 7 EB-dosing $(P<0.05)$ and insignificantly on day 45 post-EB dosing $(P>0.05)$. On the other hand, the AST levels of $1 \mathrm{X}$ and 10X groups were significantly different on day 28 as well as on day 45 post-EB dosing $(P<0.05)$, perhaps due to EB-induced stress at highest dose. The results on the significant elevations in the serum ALT and AST levels of Nile tilapia are comparable to those of the effects of rifampicin or tetracycline-induced hepatic dysfunction in rats (Yin et al., 2006). The ALT and AST levels on day 45 post-EBdosing were, however, significantly higher than those of day 0 , thus implying the persistent effect of EB on liver functioning.

The elevated serum creatinine level is an indication of kidney damage, low glomerular filtration rate, muscular dystrophia and physical exertion in organisms (Zaki et al., 2010). The serum creatinine levels $\left(0.88-1.045 \mathrm{mg} \mathrm{dl}^{-1}\right)$ of the control group were within the permissible levels $\left(0.20-1.10 \mathrm{mg} \mathrm{dl}^{-1}\right)$ as noted earlier in tilapia, raised in different culture systems (Hrubec et al., 2000; Mauel et al., 2007). The impact of EB was apparent on the $1^{\text {st }}$ day of dosing. The creatinine levels increased significantly to 1.69 and $1.945 \mathrm{mg} \mathrm{dl}^{-1}$ in $1 \mathrm{X}$ EB-fed fish on day 1 and day $7 \mathrm{~EB}-$ dosing, respectively. There existed a significant reduction in the creatinine levels to 1.425 and $1.195 \mathrm{mg} \mathrm{dl}^{-1}$ on day 28 and day 45 post-EB dosing $(P<0.05)$. A parallel trend was observed in $10 \mathrm{X}$ EB-feed fed group, where a creatinine level of $2.37 \mathrm{mg} \mathrm{dl}^{-1}$ was observed on day $1 \mathrm{~EB}-$ dosing. Its level increased to $2.685 \mathrm{mg} \mathrm{dl}^{-1}$ on day 7 EB-dosing (Fig. 2d). The creatinine levels increased approximately 2.21 folds in the $1 \mathrm{X}$ group and by 3.05 folds in $10 \mathrm{X}$ group in 7 days of EB-dosing in a dose-dependent manner, thereby indicating the nephrotoxic potential of EB and obviously impaired kidney function. Although the creatinine levels reduced significantly during post-EB dosing period, it never reached the level recorded on day 0 . These observations suggested an improvement in the kidney function, yet the fish could not recover fully even after 45 days of cessation of EB-dosing. This would highly affect the growth and production of Nile tilapia.

CRP level was evaluated in this study as a possible indicator of physiological state in Nile tilapia exposed to EB. Güleç 

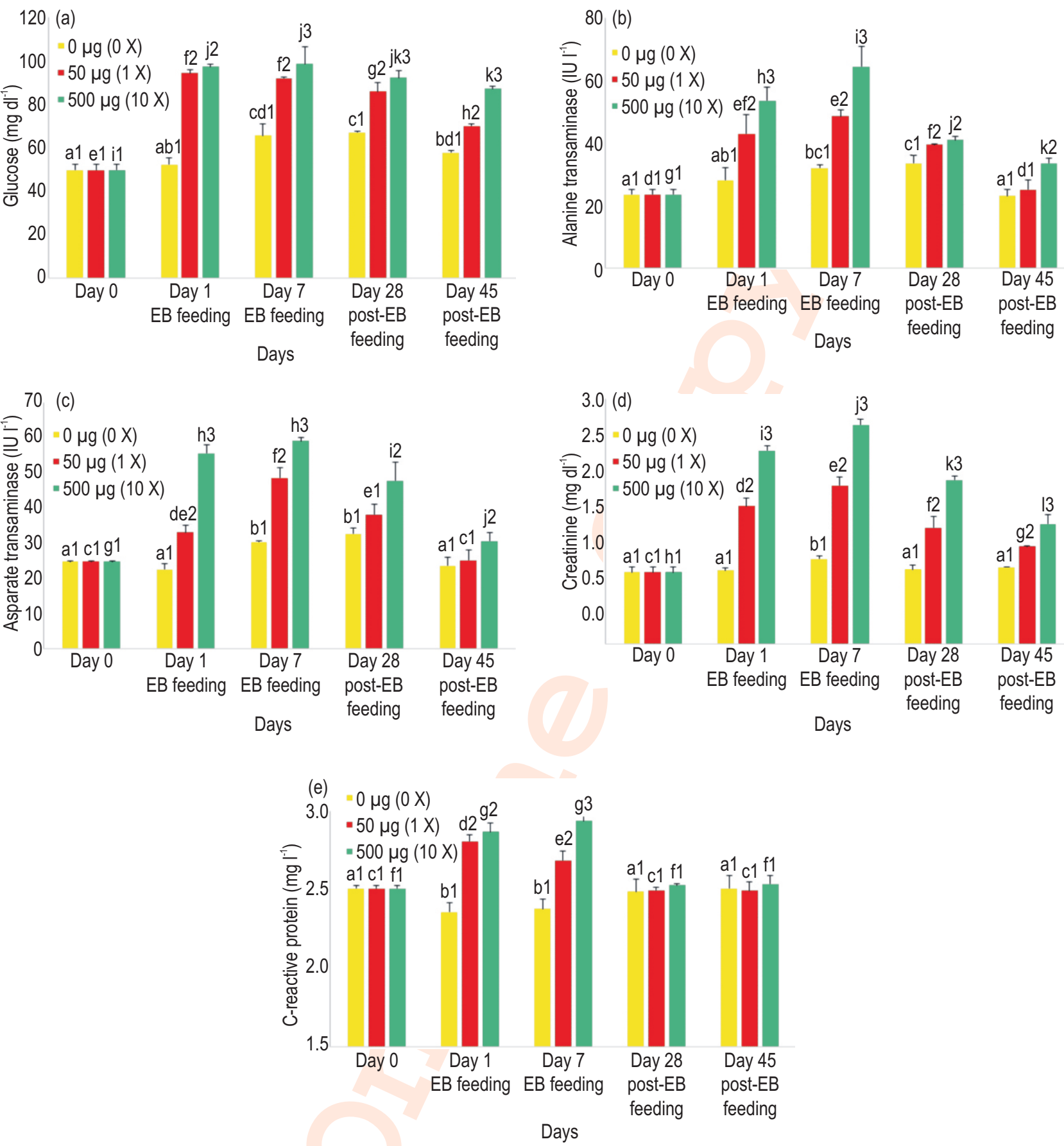

Fig. 2 : Levels of (a) Serum glucose, (b)Alanine transaminase (ALT), (c)Asparate transaminase (AST), (d) Creatinine and (e) C-reactive protein (CRP) in Emamectin benzoate (EB) fed Oreochromis niloticus at 50 and $500 \mu \mathrm{g} \mathrm{kg} \mathrm{fish}{ }^{-1}$ day ${ }^{-1}$ for 7 consecutive days. Yellow bars sharing common alphabets differed insignificantly $(P>0.05)$; Magenta bars sharing common alphabets differed insignificantly $(P>0.05)$; Cyan bars sharing common alphabets differed insignificantly $(P>0.05)$; Bars sharing common numerical among the treatment groups on the particular day of sampling differed insignificantly $(P>0.05)$.

and Cengizler (2012) recorded a serum CRP level of $2.97 \mathrm{mg} \mathrm{dl}^{-1}$ in control tilapia, which was lower than the levels recorded in the control group of the present study $\left(2.36-2.51 \mathrm{mgl}^{-1}\right)$. The impact of EB-dosing was sensed on $1^{\text {st }}$ day as the fish responded strongly by synthesizing CRP as an acute-phase reactant. The 1X EBfeed fed group had a significant increase in the CRP level on day 7 (2.69 mg l-1), which then decreased to 2.50 and $2.495 \mathrm{mg} \mathrm{l}^{-1}$ $(P<0.05)$ on day 28 and day 45 post-EB dosing, respectively. Its 
rapid increase during EB-dosing period conceivably suggested its role in Nile tilapia's defence as part of inflammatory and innate immune response, and the pervasive physiological response of the liver. The results on the significant difference in the CRP levels between the control and $1 \mathrm{X}$ group in 7 days of EB-dosing demonstrated that even the recommended dose of EB ( $50 \mu \mathrm{g} \mathrm{kg}$ fish $^{-1}$ day $^{-1}$ ) may elicit the inflammatory response in Nile tilapia and synthesize more CRP in tropical conditions. The 10X EB-fed fish also had a comparable trend in the serum CRP levels. The maximum CRP value of $2.94 \mathrm{mg} \mathrm{I}^{-1}$ was noted on day $7 \mathrm{~EB}$-dosing, which then decreased significantly to 2.53 and $2.54 \mathrm{mg} \mathrm{I}^{-1}$ $(P<0.05)$ on day 28 and day 45 post-EB dosing (Fig. 2e). The differences in the CRP levels of control and $1 X$ groups on day 1 EB-dosing, and $1 X$ and 10X EB-feed groups $(P<0.05)$ on day 7 EB-dosing were significant $(P<0.05)$. Despite reduction, the differences in the CRP levels on day 28 post-EB dosing were insignificant, thus signifying that the degree of inflammatory responses was same regardless of EB dose. Likewise Oncorhynchus mykiss exposed to anti-ectoparasite chemicals, viz., formalin, metrifonate and potassium permanganate showed increased CRP levels. Its levels in the treated fish decreased afterwards to lower levels than in unexposed fish (Kodama et al., 2004). Our results of such negative acute-phase reactant substantiate the findings of Kodama et al. (2004). According to them, the biological significance of increase and decrease of CRP levels due to exposure to aquadrugs is not clear. The upsurge of CRP in fish upon exposure to EB implied that CRP is important in host defence mechanisms. Involvement of CRP is, therefore, important in the overall response to toxic exposure, fitting into the apparently reciprocating relationship between immune and chemical detoxifying systems (Kodama et al., 2004). The results of the present study suggested that the effects of EB on serum biomarkers are revocable. Nevertheless, it did not reach normalcy, except for ALT, AST and CRP, even after 45 days of dosing at the recommended dose (50 $\mu \mathrm{g}$ EB kg biomass ${ }^{-1}$ day $\left.^{-1}\right)$. This raises concern on the effectiveness of oral EB-dosing in a tropical Indian condition.

In conclusion, the results of this study demonstrated that the physiological state of apparently healthy Nile tilapia was persuaded by oral EB-dosing. The baseline data on the serum markers and biomass production would provide a valid reference for researchers and aquaculturists in assessing the health condition of cultured Nile tilapia after EB administration in tropical condition.

\section{Acknowledgments}

The authors thank the Vice-Chancellor, West Bengal University of Animal and Fishery Sciences, Kolkata for providing necessary facilities to carry out the work. The work was supported by the Indian Council of Agricultural Research, Government of India, New Delhi under the All India Network Project on Fish Health (GrantF. No. CIBA/AINP-FH/2015-16 dated 02.06.2015).

\section{References}

Armstrong, R., D. MacPhee, T. Katz and R. Endris: A field efficacy evaluation of emamectin benzoate for the control of sea lice in Atlantic salmon. Can Vet J., 41, 607-612 (2000).

Athanassopoulou, F., I.S. Pappas and K. Bitchava: An overview of the treatments for parasitic disease in Mediterranean aquaculture. In: The use of veterinary drugs and vaccines in Mediterranean aquaculture (Eds.: C. Rogers and B. Basurco). Ciheam, Zaragoza, pp. 65-83 (2009).

Bakker, A.J. and M. Mücke: Gammopathy interference in clinical chemistry assays: Mechanisms, detection and prevention. Clin. Chem. Lab. Med., 45, 1240-1243 (2007).

Barraza, M.L., C.E. Coppock, K.N. Brooks, D.L. Wilks, R.G. Saunders and G.W. Latimer: Iron sulfate and feed pelleting to detoxify free gossypol in cottonseed diets for dairy cattle. J. Dairy Sci., 74, 34573467 (1991).

Boyd, C.E.: Water quality in warm water fish ponds. Alabama Agriculture Experiment Station, Auburn University, Alabama, p. 482 (1979).

Burg, R.W. and E.O. Stapley: Isolation and production of the producing organism. In: Ivermectin and Abamectin (Eds.: W.C. Campbell). Springer-Verlag, New York., pp. 24-32 (1990).

Campbell, W.C.: Ivermectin and Abamectin. Springer-Verlag, New York (1990).

Canli, M.: Effect of $\mathrm{Hg}, \mathrm{Cr}$, Ni on glycogen reserves and protein levels in tissues of Cyprinus carpio. Turk. J. Zool., 20, 161-168 (1996).

Chen, C.Y., G.A. Wooster and P.R. Bowser: Comparative blood chemistry and histopathology of tilapia infected with Vibrio vulnificus or Streptococcus iniae or exposed to carbon tetrachloride, gentamicin, or copper sulphate. Aquaculture, 239, 421-443 (2004).

Chen, C.Y., G.A. Wooster, R.G. Getchell, P.R. Bowser and M.B. Timmons: Blood chemistry of healthy, nephrocalcinosis affected and ozone treated tilapia in a recirculation system, with application of discriminant analysis. Aquaculture, 218, 89-102 (2003).

Dange, D.A.: Changes in carbohydrate metabolism in tilapia, Oreochromis mossambicus, during short-term exposure to different types of pollutants environmental pollutants. Environ. Pollut. SeriesA, Ecol. Biol., 41, 165-177 (1986).

Feng, L., B. Cui, D. Yang, C. Wang, Z. Zeng, Y. Wang, C. Sun, X. Zhao and $\mathrm{H}$. Cui: Preparation and evaluation of emamectin benzoate solid microemulsion. J. Nanomater., 3, 1-7 (2016).

Feri, J., C.C. Heuck, W. Riesen, H. Lang, P.G. Hill, N.M. EL-Nageh and L. Poller: Production of basic diagnostic laboratory reagents, Eastern Mediterranean Series: 11 (WHO Regional Publication) pp. 40-44 (1995).

Güleç, A.K. and I. Cengizler: Determination of acute phase proteins after experimental Streptococcus iniae infection in tilapia (Oreochromis niloticus L.). Turk. J. Vet. Anim. Sci., 36, 380-387 (2012).

Hanson, S.K., J.E. Hill, C.A. Watson, R.P.E. Yanong and R. Endris: Evaluation of emamectin benzoate for the control of experimentally induced infestations of Argulus sp. in goldfish and koi carp. J. Aquat. Anim. Hlth., 23, 30-34 (2011).

Hrubec, T.C., J.L. Cardinante and S.A. Smith: Hematology and serum chemistry reference intervals for cultured tilapia (Oreochromis hybrid). Vet. Clin. Pathol., 29, 7-12 (2000).

Junge, W., B. Wilke, A. Halabi and G. Klein: Determination of reference intervals for serum creatinine, creatinine excretion and creatinine clearance with an enzymatic and a modified Jaffé method. Clin. Chim. Acta., 344, 137-148 (2004). 
Kodama, H., Y. Matsuoka, Y. Tanaka, Y. Liu, T. Iwasaki and S. Watarai: Changes of $\mathrm{C}$-reactive protein levels in rainbow trout (Oncorhynchus mykiss) sera after exposure to anti-ectoparasitic chemicals used in aquaculture. Fish Shellfish Immunol., 16, 589597 (2004).

Manjunatha, B., J.O. Tirado, P.F. Salas, D.R. Ortiz, G.J. Mohiddin, V.S. Reddy, M.N. Raju and M. Selvanayagam: Enzyme activities of Nile tilapia (Oreochromis niloticus) during lethal and sublethal exposure to cypermethrin. Der. Pharma. Chem., 7, 279-283 (2015).

Martínez-Porchas, M., L.R. Martínez-Cordova and R. Ramos-Enriques: Cortisol and glucose: Reliable indicators of fish stress?. Pan-Am. J. Aquat. Sci., 4, 158-178 (2009).

Mauel, M.J., D.L. Miller and A.L. Merrill: Hematologic and plasma biochemical values of healthy hybrid tilapia (Oreochromis aureus $\times$ Oreochromis nilotica) maintained in a recirculating system. J. Zoo. Wildlife Med., 38, 420-424 (2007).

McKellar, Q.A. and H.A. Banchaoui: Avermectins and Milbemycins. J. Vet. Pharmacol. Ther., 19, 331-351 (1996).

MSD Animal Health: SLICE $®$ technical monograph. Merck Animal Health, Whitehouse Station, New Jersey, USA, p. 32 (2012).

Ng, W.K. and N. Romano: A review of the nutrition and feeding management of farmed tilapia throughout the culture cycle. Rev. Aquac., 5, 220-254 (2013).

Roberts, R.J.: Fish Pathology. John Wiley \& Sons, New Delhi (2012).

Roy, W.J., I.H. Sutherland, H.D.M. Roger and K.J. Varma: Tolerance of Atlantic salmon, Salmo salar L. and rainbow trout, Oncorhynchus mykiss (Walbaum), to emamectin benzoate, a new orally administered treatment for sea lice. Aquaculture, 184, 19-29 (2000).

Sahoo, P.K., J. Mohanty, S.K. Garnayak, B.R. Mohanty, B. Kar, J.K. Jena, J.K. and H. Prasanth: Genetic diversity and species identification of Argulus species collected from different aquaculture regions of India using RAPD-PCR. Aquac. Res., 44, 220-230 (2013).

Sanders, P. and G. Swan: Emamectin benzoate. In: Joint FAO/WHO Expert Committee on Food Additives, editors. Residue evaluation of certain veterinary drugs. Food and Agriculture Organization of the United Nations, Rome, pp. 23-37 (2014).

Stone, J., I.H. Sutherland, C. Sommerville, R.H. Richards and K.J. Varma: The efficacy of emamectin benzoate as an oral treatment of sea lice, Lepeophtheirus salmonis (Kroyer), infestations in Atlantic salmon, Salmo salarL. J. Fish Dis., 22, 261-270 (1999).

Trinder, P.: Determination of glucose in blood using glucose oxidase with an alternative oxygen receptor. Ann. Clin. Biochem., 6, 24-27 (1969).

Whyte, S.K., J.D. Westcott, P. Byrne and K.L. Hammell: Comparison of the depletion of emamectin benzoate (SLICE $®$ ) residues from skeletal muscle and skin of Atlantic Salmon (Salmo salar), for multiple dietary dose regimens at $10^{\circ} \mathrm{C}$. Aquaculture, 315, 228235 (2011).

Yin, H.Q., M. Kim, J.H. Kim, G. Kong, M.O. Lee, K.S. Kang, B.I. Yoon, H.L. Kim and B.H. Lee: Hepatic gene expression profiling and lipid homeostasis in mice exposed to steatogenic drug, tetracycline. Toxicol. Sci., 94, 206-216 (2006).

Zaki, M.S., O.M. Fawzi and J. El-Jackey: Pathological and biochemical studies in Tilapia nilotica infected with Saprolegnia parasitica and treated with potassium permanganate. Am. Eurasian J. Agric. Environ. Sci., 3, 677-680 (2008).

Zaki, M.S., S. Moustafa, O.M. Fawzi, H. El-Bellbasi, S. Syame and I.M. Awad: Assessment of the hazardous effect of lead pollution on Tilapia zilli, including hematological, biochemical and immunological parameters. Rep. Opin., 2, 82-89 (2010). 